\title{
Analysis of Mechanical and Tribological properties of Silicon incorporated Diamond Like Carbon Nanocomposite
}

\section{Sakthi Murugan}

Saveetha Institute of Medical and Technical Sciences: Saveetha University

S. Madhu ( $\nabla$ mathumarine@gmail.com )

Saveetha Institute of Medical and Technical Sciences: Saveetha University

\section{Research Article}

Keywords: CVD, DLC, Si-DLC, Nanocomposite, SEM, AFM

Posted Date: July 1st, 2021

DOl: https://doi.org/10.21203/rs.3.rs-639114/v1

License: (c) (1) This work is licensed under a Creative Commons Attribution 4.0 International License.

Read Full License 


\title{
Analysis of Mechanical and Tribological properties of Silicon incorporated Diamond Like Carbon Nanocomposite
}

\author{
V. Sakthi Murugan ${ }^{1}, * S$ Madhu $^{2}$ \\ 1,2 Department of Automobile Engineering Saveetha School of Engineering, Saveetha \\ Institute of Medical and Technical Sciences, Chennai, Tamil Nadu, India \\ *smadhusimts@gmail.com
}

\begin{abstract}
:
The Silicon ( $\mathrm{Si}$ ) contained diamond like carbon (DLC) nanocomposite were prepared by using thermal chemical vapour deposition (CVD) technique by varying the acetylene $\left(\mathrm{C}_{2} \mathrm{H}_{2}\right)$ flowrates. The scanning electron microscope (SEM) results showed a smoother surface of nanocomposite at low $\mathrm{C}_{2} \mathrm{H}_{2}$ flowrates. The atomic force microscope (AFM) reveals the increase of particle size and surface roughness of the composite with respect to the $\mathrm{C}_{2} \mathrm{H}_{2}$ flowrates. The mechanical properties were evaluated using the nanoindentation and it is observed that the hardness $(\mathrm{H})$ and young's modulus $(\mathrm{E})$ of the nanocomposite increases with increase of the $\mathrm{C}_{2} \mathrm{H}_{2}$ flow rate. The internal stress $(\boldsymbol{\sigma})$ was computed by using Stoney's equation and it is noticed that due to the incorporation of Si the residual stress significantly decreased. The tribological properties of the nanocomposite were analysed by computing the $H / E, H^{3} / E^{2}$, plasticity index (PI) and elasticity index (EI). The results showed that the Si incorporated nanocomposite (Si-DLC) has an excellent tribological properties.
\end{abstract}

Key word: CVD, DLC, Si-DLC, Nanocomposite, SEM, AFM

\section{Introduction:}

In the recent years carbon-based coatings or nanocomposites have been extensively used on various mechanical components like bearings, cutting tool, gears, engine parts, and other drivetrain components due to their outstanding tribological properties [1-3]. DLC is one of the carbon coating which has been attracted to the scientists due to its excellent mechanical, tribological, optical and biomedical properties. DLC coatings are usually amorphous, having various fractions of sp3 and $\mathrm{sp} 2$ hybridized $\mathrm{C}-\mathrm{H}$ and $\mathrm{C}-\mathrm{C}$ bonding. Due to the excellent properties of the coating, it is widely used in many industrial applications [4-6]. Unfortunately, DLC coating have some disadvantages like high residual stress, weak adhesion with the substrate, and bad resistance to wear under liquid environments. The above problem of DLC 
film can be overcome by adding various metals (Al, $\mathrm{Ag}, \mathrm{Fe}, \mathrm{Mo}, \mathrm{Al}, \mathrm{Cu})$ and semiconductors ( $\mathrm{Si}, \mathrm{Ge}$ ) into the coatings and tends to form carbon-based nanocomposites. When various metallic or semiconductor elements are doped into DLC, they normally develop metal or semiconductor carbides within the amorphous hydrocarbon (HC) network, which leads to reduce the residual stresses [7-9]. Ghadai et al. developed Si-DLC nanocomposite using thermal CVD and the results showed the improvement of mechanical and tribological properties [10]. Fujimoto et al. deposited Si based DLC nanocomposite using DC pulsed plasma CVD and observed the improvement of mechanical and tribological properties [11]. Li et al. examined the nano-tribological and mechanical properties of Si added DLC composite and noticed that adding Si into DLC can have substantial enhancements in the wear resistance of DLC composite [12]. Liu et al. produced the Si added DLC nano composite by using magnetron sputtering and their results showed a considerable increase of tribological properties due to the inclusion of silicon. The authors achieved a minimum COF of 0.05 which signify the tribological enhancement of the composites [13]. Kim et al. developed Si-DLC nano composite using filtered cathodic vacuum arc deposition technique and noticed the COF value of 0.05 [14].

From the above literature it has been observed that Si-DLC nano composite has an excellent mechanical, tribological, morphological properties. It is also noticed that most of the researchers have deposited Si-DLC nanocomposite either by using PECVD techniques or physical vapour deposition (PVD) techniques. Very few works have done by using thermal CVD by varying the hydrogen $\left(\mathrm{H}_{2}\right)$ or argon or nitrogen $\left(\mathrm{N}_{2}\right)$. However, the effect of hydrocarbon gas like acetylene $\left(\mathrm{C}_{2} \mathrm{H}_{2}\right)$ or methane $\left(\mathrm{CH}_{4}\right)$ over the mechanical, tribological and morphological properties have not been discussed by the researchers. Therefore, in the present work the effect of the flow rate $\mathrm{C}_{2} \mathrm{H}_{2}$ over the mechanical, morphological, compositional and tribological properties of Si-DLC nanocomposite have been extensively discussed.

\section{Experimental Details}

In the present case Silicon ( $\mathrm{Si}$ ) incorporated DLC nanocomposites were synthesized over ptype $\mathrm{Si}$ substate using thermal CVD displayed in fig. 1. Before the synthesis of the nanocomposite, the substrates were treated by using Radio Corporation of America (RCA) cleaning procedure to eliminate the impurities. After the treating with RCA cleaning procedure, the substrates were placed over a thick ceramic plate within the chamber for the deposition. For the silicon incorporation, Silicon powder were purchased from Sigma-Aldrich and the size 
of the particles were less than $45 \mu \mathrm{m}$. The Si powder was kept within a ceramic boat, and it was placed in the middle of the ceramic chamber. The distance between the ceramic plate and ceramic boat was around $5 \mathrm{~cm}$. The deposition temperature $\left(\mathrm{T}_{\mathrm{d}}\right)$ and $\mathrm{H}_{2}$ flow rate were kept constant as $1000^{\circ} \mathrm{C}$ and $20 \mathrm{sccm}$, respectively. Four different samples were made by changing the acetylene $\left(\mathrm{C}_{2} \mathrm{H}_{2}\right)$ flow rate from $5 \mathrm{sccm}$ to $11 \mathrm{sccm}$. The deposition time was kept constant as 120 minutes. The working and base pressure within the CVD were kept at 500 mTorr and $5 \times 10^{-6}$ Torr, respectively. For the synthesis of nanocomposite, the rising rate of temperature was $5{ }^{\circ} \mathrm{C} / \mathrm{min}$ and declining rate of temperature was $3{ }^{\circ} \mathrm{C} / \mathrm{min}$. CSM Instruments having model no NHTX 55-0019 with a Berkovich diamond indenting tip was used to find the mechanical properties. The radius of curvature of the indenter tip was $\sim 100 \mathrm{~nm}$. At four various points the indentation was done at a peak load of $20 \mathrm{mN}$ and the average values were considered as a result. Oliver-Pharr method was used to compute the hardness $(\mathrm{H})$ and young's modulus $(\mathrm{E})$ of the nanocomposites by taking the initial gradient of the unloading portion of the load displacement curve [15]. Dektak profilometer having model name Dektak V 300 was used to find the thickness of the coatings. The radius of the diamond stylus used in the Dektak profilometer was $2.5 \mu \mathrm{m}$. Scanning Electron Microscope (Model: EVO MA18 Oxford EDS (X-act) was used for analysing the surface morphology of the Si-DLC nanocomposite. While using SEM the operating voltage was $10 \mathrm{kV}$, magnification was in the range of $1 \mathrm{x}$ to 100,000 $\mathrm{x}$ and scale was of $10 \mu \mathrm{m}$. Innova SPM atomic force microscope (AFM) with a $100 \mu \mathrm{m}$ scanner was used to find the average roughness $(\mathrm{Ra})$ and particle size of the nanocomposites.

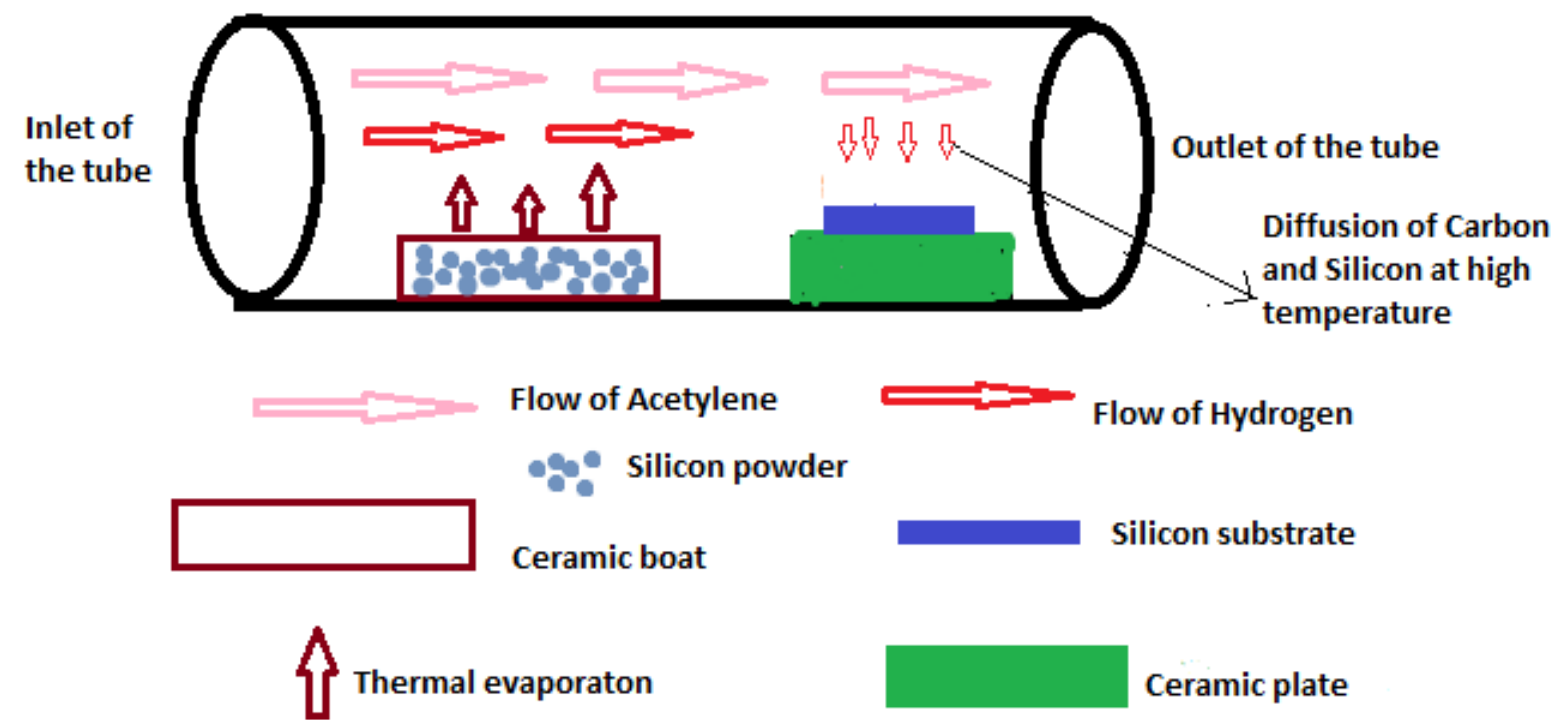

Fig. 1. Schematic diagram of thermal CVD for the deposition of Si-DLC nanocomposite 


\section{Result and Discussion}

\subsection{Thickness estimation of Si-DLC nanocomposite using Dektak profilometer}

Table 1 shows the thickness of the $\mathrm{Si}$-DLC nano composite with respect to various $\mathrm{C}_{2} \mathrm{H}_{2}$ flow rate. For each sample, the stylus of the profilometer moved from one point to other at four distinct locations and the average step heights were taken for the estimation of coating thickness. From the table it has been observed that the coating thickness of the nano composite increases minutely with respect to the $\mathrm{C}_{2} \mathrm{H}_{2}$ flow rate. The minimum and maximum coating thickness was observed as $6.32 \pm 0.14$ and $6.52 \pm 0.24 \mu \mathrm{m}$ for the nanocomposite deposited at $5 \mathrm{sccm}$ and $11 \mathrm{sccm}$, respectively. The increase of the thickness of Si-DLC composite may be due to the deposition of more carbon atom at higher $\mathrm{C}_{2} \mathrm{H}_{2}$ flow rates.

Table 1: Variation of thickness of Si-DLC nanocomposite with respect to $\mathrm{C}_{2} \mathrm{H}_{2}$ flow rate

\begin{tabular}{|l|c|c|c|c|}
\hline Sample Code & $\begin{array}{l}\text { flow rate of } \\
\text { hydrogen }(\mathbf{s c c m})\end{array}$ & $\begin{array}{l}\text { Deposition temp. } \\
\left({ }^{\circ} \mathbf{C}\right)\end{array}$ & $\begin{array}{l}\text { flow rate of } \\
\text { acetylene } \\
(\mathbf{s c c m})\end{array}$ & Thickness $(\boldsymbol{\mu m})$ \\
\hline Si-DLC NC1 & 20 & 1000 & 5 & $6.32 \pm 0.14$ \\
\hline Si-DLC NC2 & 20 & 1000 & 7 & $6.38 \pm 0.17$ \\
\hline Si-DLC NC3 & 20 & 1000 & 9 & $6.5 \pm 0.23$ \\
\hline Si-DLC NC4 & 20 & 1000 & 11 & $6.52 \pm 0.24$ \\
\hline
\end{tabular}

\subsection{Morphological and Compositional analysis of the Nanocomposite using SEM and EDS}

Fig. 2 indicates the morphology of Si-DLC nano composite with respect to various flow rate of $\mathrm{C}_{2} \mathrm{H}_{2}$. From the SEM images it has been noticed that the Si-DLC nanocomposite deposited at low $\mathrm{C}_{2} \mathrm{H}_{2}$ flow rate $(5 \mathrm{sccm}$ and $7 \mathrm{sccm})$ seems to have very smooth and uniform coating. At higher $\mathrm{C}_{2} \mathrm{H}_{2}$ flow rate $(9 \mathrm{sccm}$ and $11 \mathrm{sccm})$ some agglomerated Silicon particles are appeared 
over the surface of the nanocomposite. The formation of agglomerated particles on the nanocomposite surface may be due to incomplete melting and evaporation at higher $\mathrm{C}_{2} \mathrm{H}_{2}$ flow rate within the chamber [16]. The elemental composition of Si-DLC nanocomposite at various $\mathrm{C}_{2} \mathrm{H}_{2}$ flowrate have been analysed using EDS and shown in table 2. The EDS result of Si-DLC Nanocomposite deposited at $7 \mathrm{sccm} \mathrm{C}_{2} \mathrm{H}_{2}$ flowrate is shown in fig. 3. From the table it is observed that the major elements present in the composite are carbon (C) and Silicon ( $\mathrm{Si}$ ) along with some amount of oxygen. The wt. \% of the Si monotonically decreases with respect to the $\mathrm{C}_{2} \mathrm{H}_{2}$ flowrate. However, for the nanocomposite deposited at $5 \mathrm{sccm} \mathrm{C}_{2} \mathrm{H}_{2}$ flow rate have the lowest $\mathrm{Si}$ wt. \%. Similarly, the wt. $\%$ of carbon minutely increases with the increase of $\mathrm{C}_{2} \mathrm{H}_{2}$ flow rate. The increase of the wt. \% of $\mathrm{C}$ may be due to the deposition of more carbon atom at higher $\mathrm{C}_{2} \mathrm{H}_{2}$ flow rates. Also, at higher $\mathrm{C}_{2} \mathrm{H}_{2}$ flowrate the decrease of $\mathrm{Si}$ wt. \% may be due the partial evaporation of Si within the chamber [10, 13].

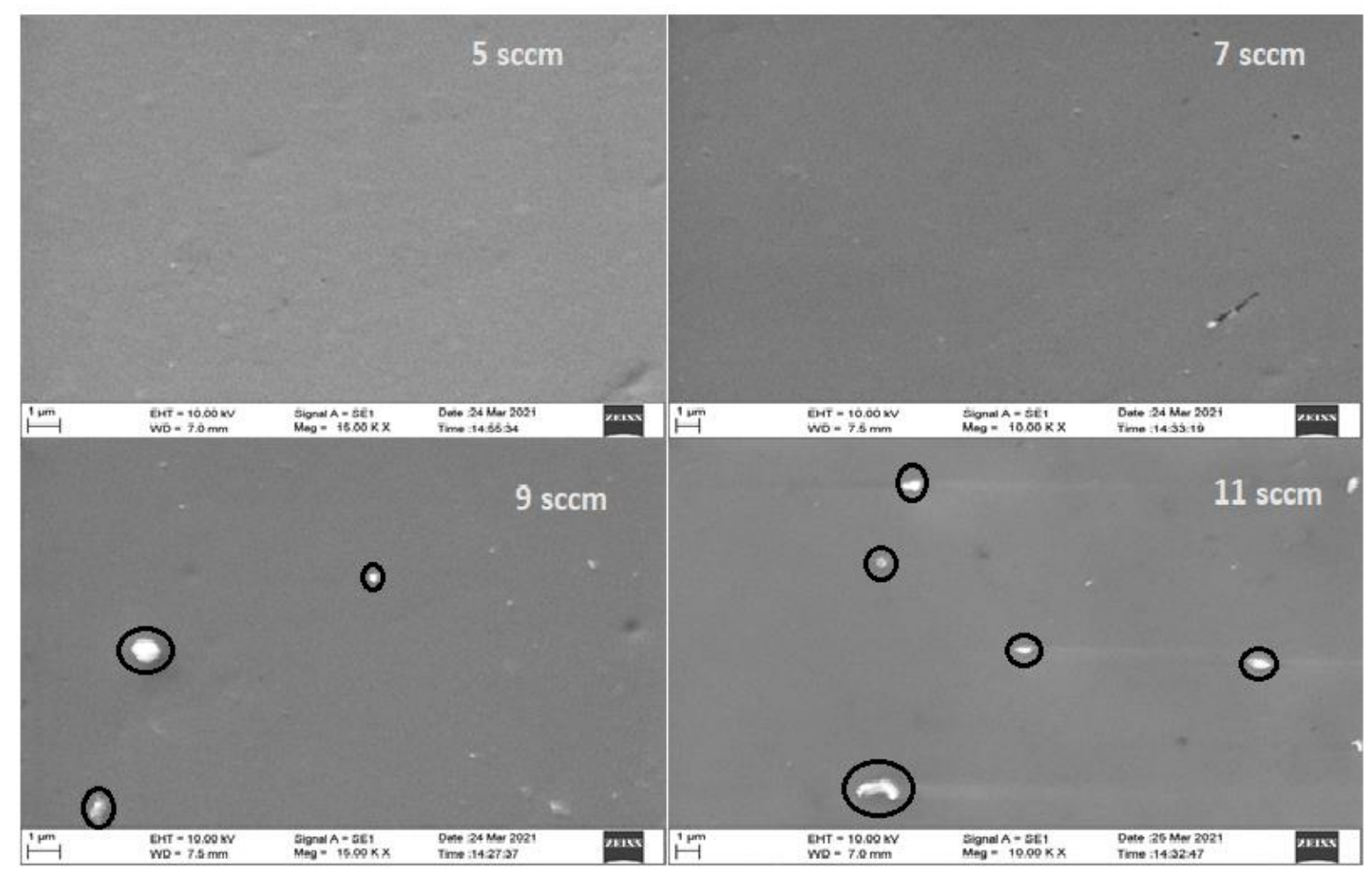

Fig. 2: Surface images of Si-DLC nanocomposite with respect to various $\mathrm{C}_{2} \mathrm{H}_{2}$ flow rate 
Table 2: Elemental Analysis using EDS

\begin{tabular}{|c|c|c|c|}
\hline $\begin{array}{c}\text { Sample } \\
\text { Code }\end{array}$ & C (at. \%) & Si (at. \%) & O (at. \%) \\
\hline Si-DLC NC1 & 86.9 & 7.5 & 5.6 \\
\hline Si-DLC NC2 & 86.2 & 10.6 & 3.2 \\
\hline Si-DLC NC3 & 87.8 & 9.1 & 3.1 \\
\hline Si-DLC NC4 & 88.2 & 8.4 & 3.4 \\
\hline
\end{tabular}

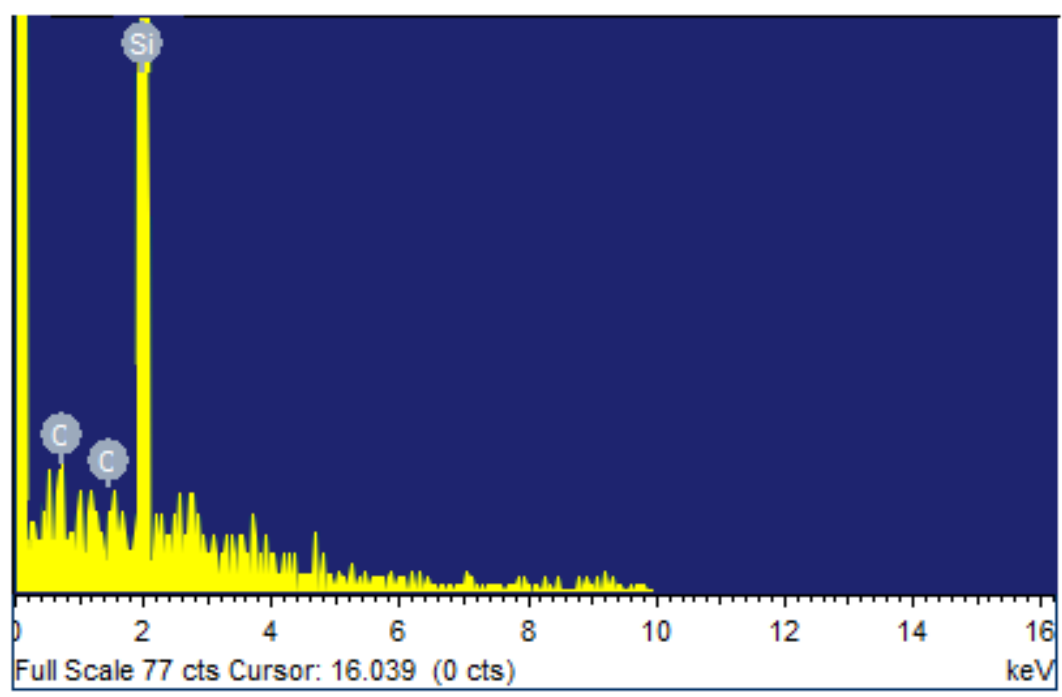

Fig. 3: EDS result of Si-DLC Nanocomposite deposited at $7 \mathrm{sccm} \mathrm{C}_{2} \mathrm{H}_{2}$ flowrate.

\subsection{Average roughness and particle size of the nanocomposite by using AFM}

The particle size and average roughness of the Si-DLC nanocomposite with respect to various $\mathrm{C}_{2} \mathrm{H}_{2}$ flow rate has been analysed using AFM and is shown in Fig. 4. For each nanocomposite sample, the surface roughness, average, and maximum particle size were computed at $10 \mu \mathrm{m}$ level. From the AFM images it has been noticed that the roughness of the nanocomposite increases from $5.6 \mathrm{~nm}$ to $12.6 \mathrm{~nm}$ with increase of $\mathrm{C}_{2} \mathrm{H}_{2}$ flow rate from $5 \mathrm{sccm}$ to $11 \mathrm{sccm}$. The increase of surface roughness may be due to the addition of more carbon into Si-DLC nanocomposite at higher $\mathrm{C}_{2} \mathrm{H}_{2}$ flow rate which increase the molecular volume. Also, the maximum and average particle size of the nanocomposite increases with respect to $\mathrm{C}_{2} \mathrm{H}_{2}$ flow rate. The maximum particle size is within the range of 6.5 to $17.2 \mathrm{~nm}$ whereas the average 
particle size is within the range of 0.2 to $0.9 \mathrm{~nm}$. Also, the density of the particle distribution of nanocomposite is more for the sample deposited at higher $\mathrm{C}_{2} \mathrm{H}_{2}$ flow rate $[16,17]$.
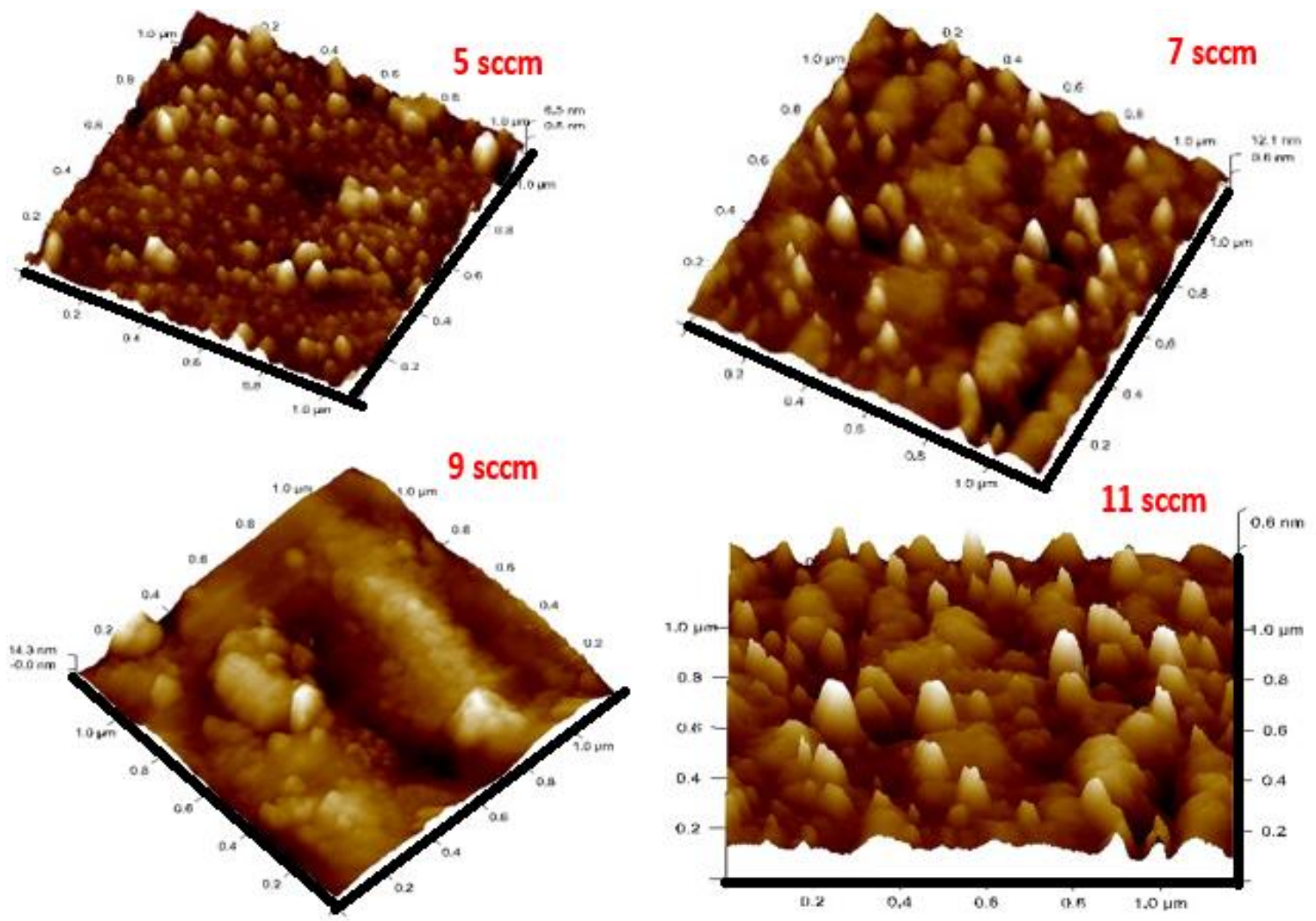

Fig. 4: AFM images of Si-DLC nanocomposite with respect to various flow rate of $\mathrm{C}_{2} \mathrm{H}_{2}$

\subsection{Mechanical properties using nanoindentation and nano scratch.}

Fig. 5 indicates the loading-unloading curve of the Si-DLC nano composite with respect to various $\mathrm{C}_{2} \mathrm{H}_{2}$ flow rate for a fixed load of $20 \mathrm{mN}$. The loading and unloading rate for the indentation was $40 \mathrm{mN} / \mathrm{min}$ and at the maximum loading $(20 \mathrm{mN})$ the holding time was $10 \mathrm{sec}$. To prevent the substrate effect maximum depth of indentation was restricted to $10 \%$ of the coating thickness. The maximum and minimum indentation depth were $326.05 \mathrm{~nm}$ and 300.66 $\mathrm{nm}$ for the Si-DLC nanocomposite deposited at $\mathrm{C}_{2} \mathrm{H}_{2}$ flowrate of $7 \mathrm{sccm}$ and $11 \mathrm{sccm}$, respectively. The decrease of indentation depth with respect to $\mathrm{C}_{2} \mathrm{H}_{2}$ flow rate shows the increase of $\mathrm{H}$ and $\mathrm{E}$ of the Si-DLC nanocomposite. Oliver and Pharr method [15] has been used to find the mechanical properties i.e. ( $\mathrm{H}$ and $\mathrm{E}$ ). The $\mathrm{H}$ and $\mathrm{E}$ can be measured by examining the unloading part of loading-unloading curve. The $\mathrm{H}$ can be calculated by using equation 1 . 


$$
H=\frac{P_{\max }}{A}
$$

Where $\mathrm{P}_{\max }$ is the highest load applied over the nano composite and A denotes the contact area of the tip of the indenter over the nanocomposite.

By using equation (2) the stiffness ( $\mathrm{S}$ ) can be calculated, and it is presented below

$$
S=\frac{d p}{d h}=2 \beta \sqrt{\frac{A}{\pi}} E_{r}
$$

By using equation (3) the elastic modulus $\left(\mathrm{E}_{\mathrm{w}}\right)$ can be calculated

$$
\frac{1}{\mathrm{E}_{\mathrm{r}}}=\frac{1-\mathrm{v}_{\mathrm{i}}^{2}}{\mathrm{E}_{\mathrm{i}}}+\frac{1-\mathrm{v}_{\mathrm{nc}}^{2}}{\mathrm{E}_{n c}}
$$

"S" is the stiffness which calculated from the upper section of the loading-unloading curve, and it provides a geometry independent equation (3) developed by Oliver [15]. The $\beta$ value is constant and it is 1.034 for Berkovich indenter and the reduced elastic modulus is denoted by $\mathrm{E}_{\mathrm{r}}$. The subscripts i represent indenter and nc represent nanocomposite.

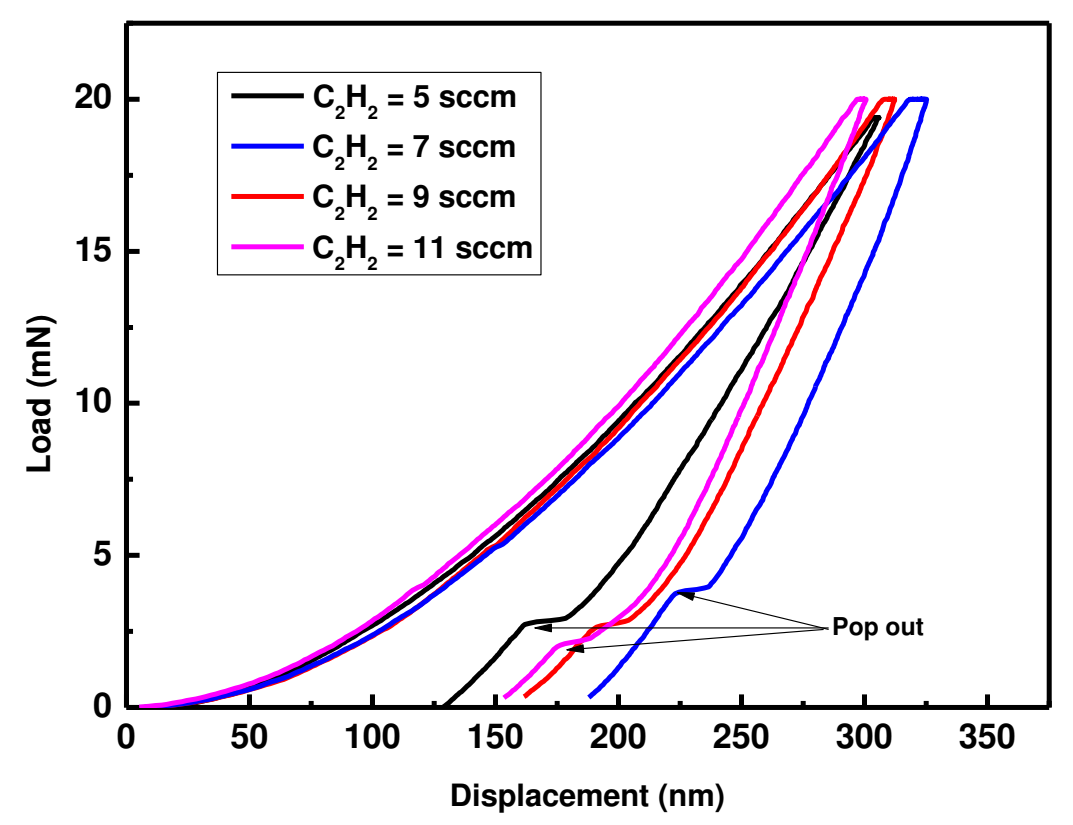

Fig. 5: Loading-unloading curve of Si-DLC nanocomposite with respect to various flow rate of $\mathrm{C}_{2} \mathrm{H}_{2}$ 
Fig. 6 illustrates the variation of $\mathrm{H}$ and $\mathrm{E}$ of the nanocomposite with respect to various flow rate of $\mathrm{C}_{2} \mathrm{H}_{2}$. The minimum and maximum $\mathrm{H}$ of the Si-DLC nanocomposite are observed as 10.06 GPa and $14.25 \mathrm{GPa}$ for the $\mathrm{C}_{2} \mathrm{H}_{2}$ flow rate of $7 \mathrm{sccm}$ and $11 \mathrm{sccm}$ respectively. Similarly the minimum and maximum E of the Si-DLC nanocomposite are observed as $127.3 \mathrm{GPa}$ and 148.41 GPa for the $\mathrm{C}_{2} \mathrm{H}_{2}$ flow rate of $7 \mathrm{sccm}$ and $11 \mathrm{sccm}$ respectively. From the trend of the graph it is noticed that the $\mathrm{H}$ and $\mathrm{E}$ of the nanocomposite increases with increase the flow rate of $\mathrm{C}_{2} \mathrm{H}_{2}$. However, at $5 \mathrm{sccm} \mathrm{C}_{2} \mathrm{H}_{2}$ flow rate the $\mathrm{H}$ of the $\mathrm{Si}$-DLC nanocomposite has been observed as $13.7 \mathrm{GPa}$ which is more than 7 and $9 \mathrm{sccm}$ and the $\mathrm{E}$ as $128.51 \mathrm{GPa}$ which is more than $7 \mathrm{sccm} \mathrm{C}_{2} \mathrm{H}_{2}$ flow rate. From the analysis using EDS it has been observed that the wt. \% of $\mathrm{Si}$ within the nanocomposite decreases with respect to the $\mathrm{C}_{2} \mathrm{H}_{2}$ flowrate. Zhao et al. synthesized Si-DLC coating using PECVD techniques, and the result showed that the $\mathrm{H}$ and $\mathrm{E}$ of the composite decreases with the increase of Si wt. \% [18]. Si doping results in a greater hydrogenation of the DLC nanocomposite which shows the stabilization of tetrahedral coordination by forming a polymeric structure. The presence of more $\mathrm{Si}$ in the nanocomposite leads to decrease the sp3 content which tends to decrease the $\mathrm{H}$ and $\mathrm{E}$ of the composite [19]. In this work the pop-out phenomenon has been observed in all the load-displacement curve and it is marked in the fig. 5. During the unloading the pop-out phenomenon is basically a result of abrupt phase change and volume expansion at the nanocomposite surface and interface edge of the indenter [20-22].

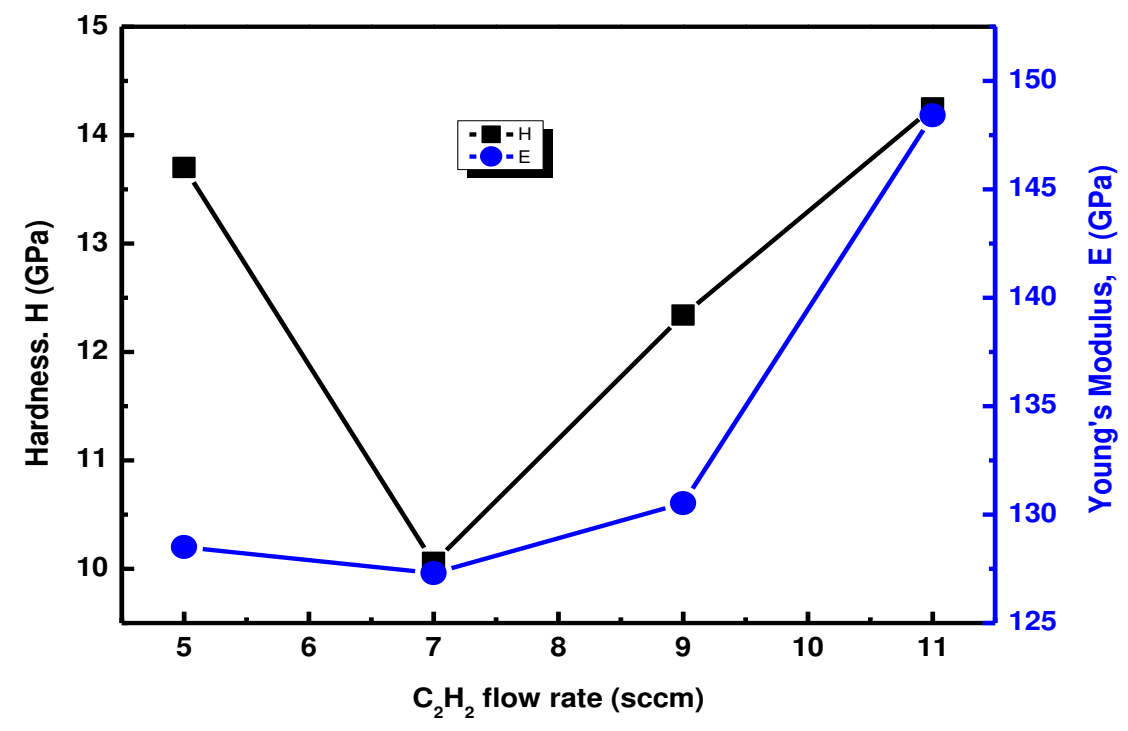

Fig. 6: $\mathrm{H}$ and $\mathrm{E}$ variation of $\mathrm{Si}-\mathrm{DLC}$ nanocomposite with respect to various flow rate of $\mathrm{C}_{2} \mathrm{H}_{2}$ 


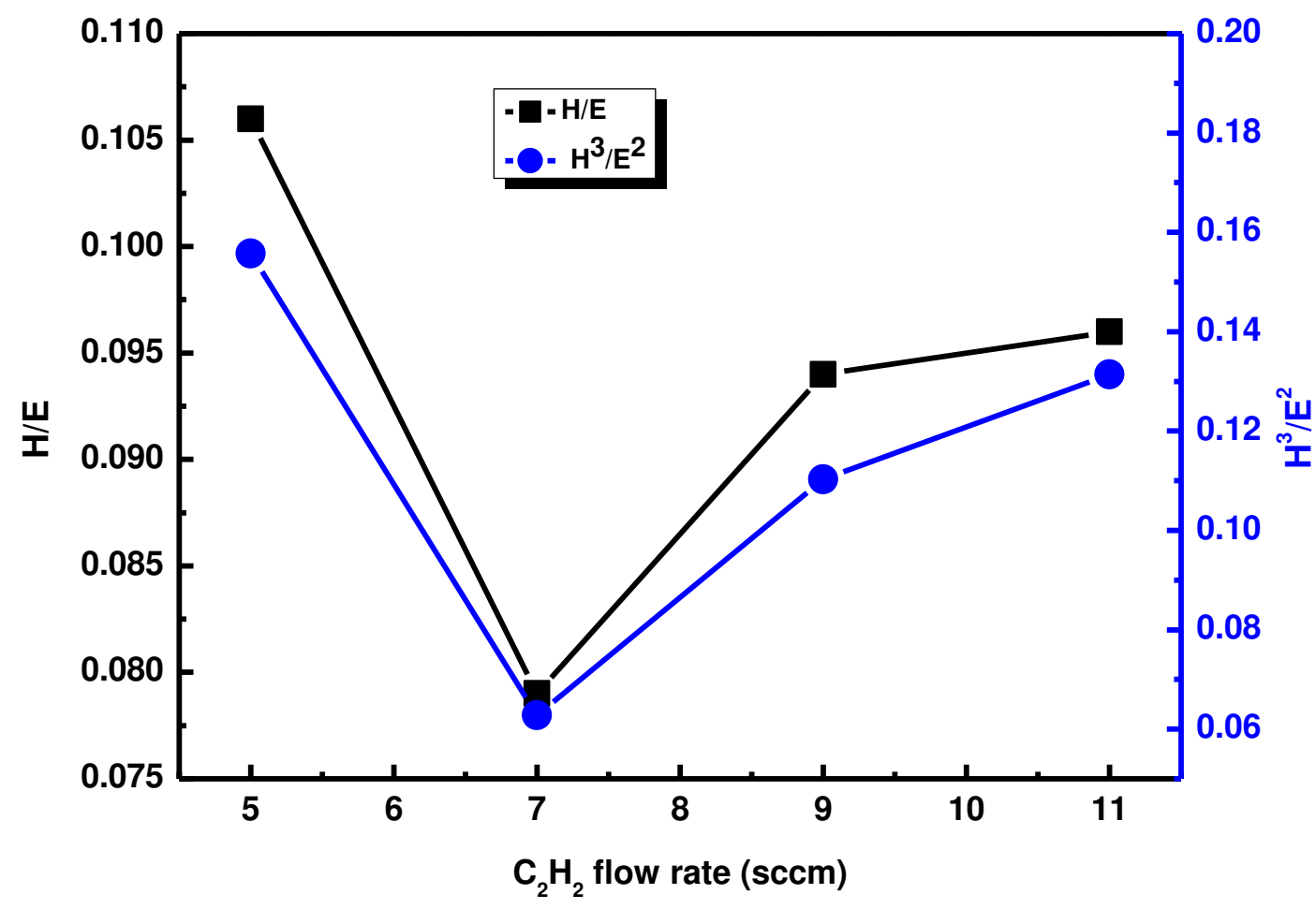

Fig. 7: $\mathrm{H}^{3} / \mathrm{E}^{2}$ and $\mathrm{H} / \mathrm{E}$ variation of Si-DLC nanocomposite with respect to various flow rate of $\mathrm{C}_{2} \mathrm{H}_{2}$

Fig. 7 illustrates the alteration of $\mathrm{H}^{3} / \mathrm{E}^{2}$ and $\mathrm{H} / \mathrm{E}$ of the nanocomposite with respect to various $\mathrm{C}_{2} \mathrm{H}_{2}$ flow rate. $\mathrm{H}^{3} / \mathrm{E}^{2}$ and $\mathrm{H} / \mathrm{E}$ are the two crucial factors to find the tribological behaviour of the Si-nanocomposite. $\mathrm{H} / \mathrm{E}$ ratio depicts the ability of the nanocomposite whereas, the $\mathrm{H}^{3} / \mathrm{E}^{2}$ ratio depicts the plastic behaviour of the composite. From the graph it has been observed that both $\mathrm{H}^{3} / \mathrm{E}^{2}$ and $\mathrm{H} / \mathrm{E}$ are following the same trend. Both $\mathrm{H}^{3} / \mathrm{E}^{2}$ and $\mathrm{H} / \mathrm{E}$ ratios decreased with the variation of $\mathrm{C}_{2} \mathrm{H}_{2}$ flow rate from 5 to $7 \mathrm{sccm}$. However, above $7 \mathrm{sccm}$ both $\mathrm{H} / \mathrm{E}$ and $\mathrm{H}^{3} / \mathrm{E}^{2}$ ratios are monotonically increased. Larger value of $\mathrm{H} / \mathrm{E}$ ratio shows the decrease of contact pressure because of the load distribution, which is applied over the large area, so higher H/E ratio is advantageous for tribological application. The higher $\mathrm{H}^{3} / \mathrm{E}^{2}$ value of indicates highly elastic behaviour whereas a low $\mathrm{H}^{3} / \mathrm{E}^{2}$ value of indicates a more noticeable plastic behaviour of the nanocomposites. The above increase of $\mathrm{H}^{3} / \mathrm{E}^{2}$ and $\mathrm{H} / \mathrm{E}$ ratios of Si-DLC nanocomposite may be because of the grain boundary sliding $[16,17]$. 


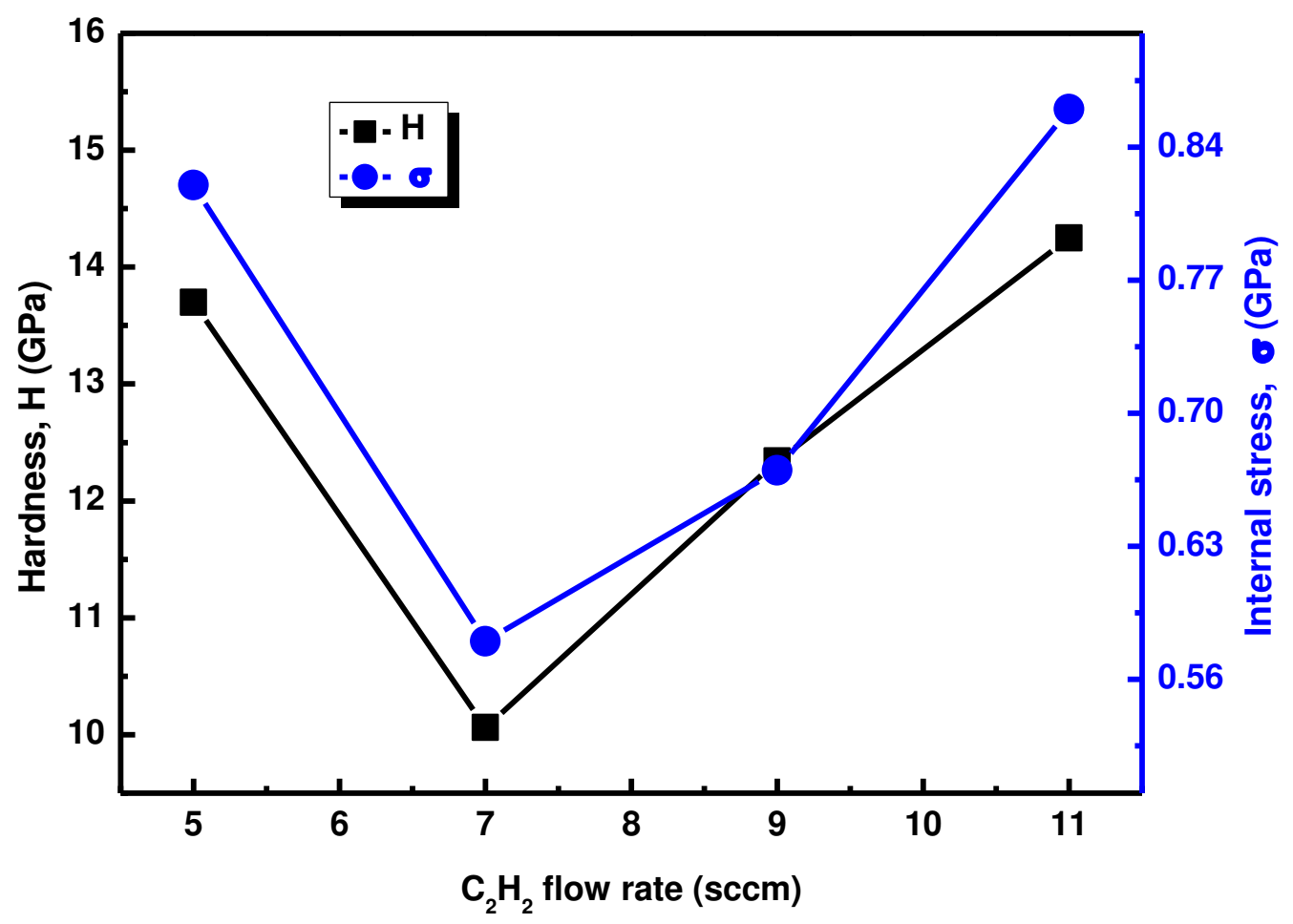

Fig. 8: Hardness and Internal stress variation of Si-DLC nanocomposite with respect to the flow rate of $\mathrm{C}_{2} \mathrm{H}_{2}$

Fig. 8 illustrates the variation of $\mathrm{H}$ and internal stress $(\boldsymbol{\sigma})$ of Si-DLC nanocomposite at various flow rate of $\mathrm{C}_{2} \mathrm{H}_{2}$ ranges from 5 to $11 \mathrm{sccm}$. In the present case Stoney equation is used to calculate the $\boldsymbol{\sigma}$ of the Si-DLC nanocomposite and it is presented in equation 4.

$$
\sigma=\frac{E_{S}}{6\left(1-v_{s}\right)} \times \frac{t_{S}^{2}}{t_{n c}}\left(\frac{1}{R_{i}}-\frac{1}{R_{f}}\right)
$$

Where $t_{n c}$ is the thickness of the Si-DLC nanocomposite and $t_{\mathrm{s}}$ is the thickness of Si substrate. $R_{i}$ and $R_{f}$ are denoted as the curvature of the coating and curvature of the substrate, respectively. The substrate's young's modulus is denoted as $\mathrm{E}_{\mathrm{s}}$ and the value is $127 \mathrm{GPa}$. The substrate poisson ratio is denoted as $v_{\mathrm{s}}$ and the values is 0.27 [23, 24]. From the fig. it has been observed that the $\boldsymbol{\sigma}$ of the nanocomposite increases with increases of $\mathrm{C}_{2} \mathrm{H}_{2}$ flow rate of from 7 sccm to $11 \mathrm{sccm}$. The minimum and maximum $\boldsymbol{\sigma}$ are $0.58 \mathrm{GPa}$ and $0.86 \mathrm{GPa}$ for the nanocomposite deposited at $\mathrm{C}_{2} \mathrm{H}_{2}$ flowrate of $7 \mathrm{sccm}$ and $11 \mathrm{sccm}$ respective. However, for the nanocomposite deposited at $\mathrm{C}_{2} \mathrm{H}_{2}$ flowrate of $5 \mathrm{sccm}$ the $\boldsymbol{\sigma}$ is $0.82 \mathrm{GPa}$. The $\boldsymbol{\sigma}$ is compressive 
in nature and the value of $\sigma$ increases due to the decrease of $\mathrm{Si}$ wt. $\%$ with respect to the $\mathrm{C}_{2} \mathrm{H}_{2}$ flow rate [25].

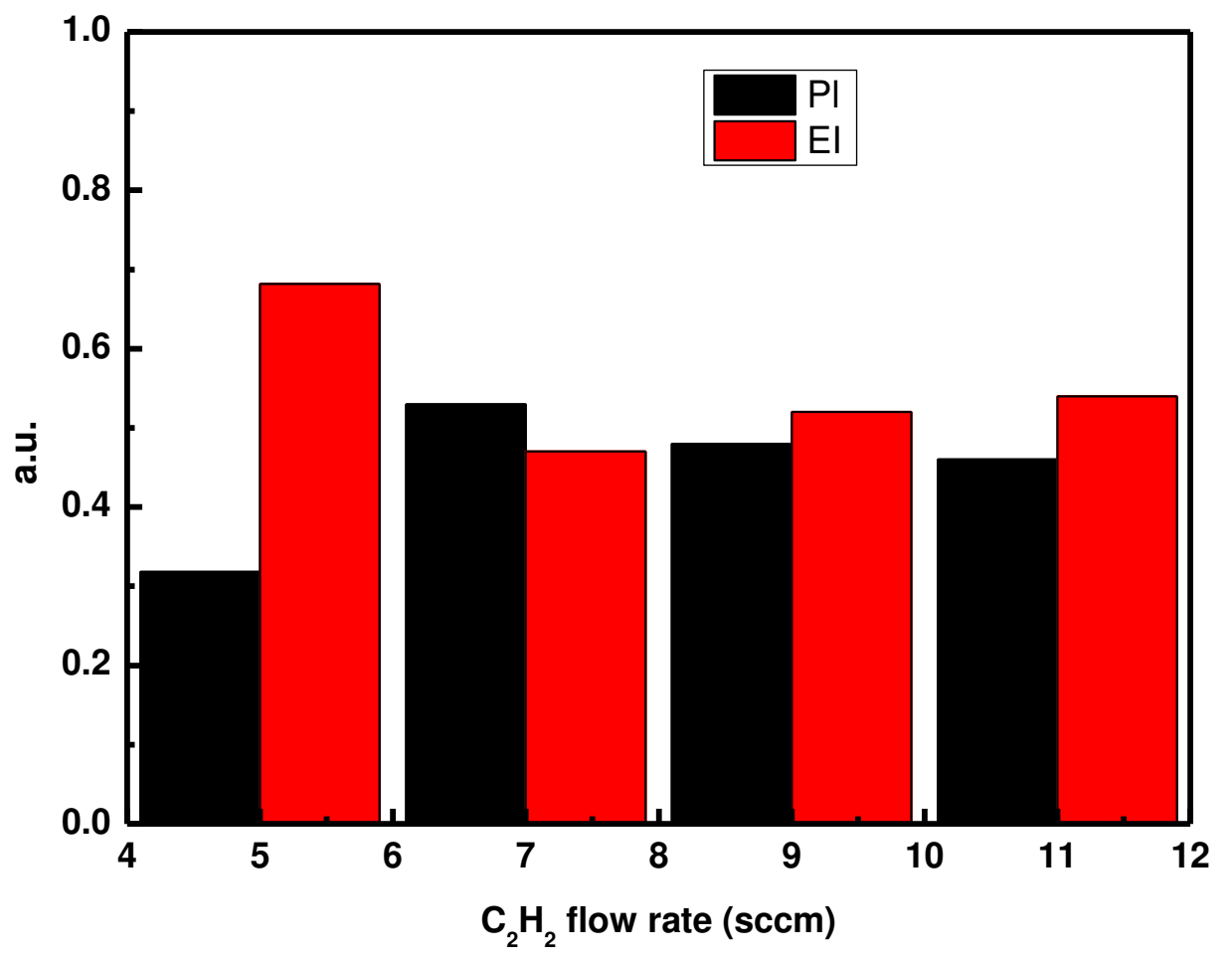

Fig. 9: Plasticity Index (PI) and Elasticity Index (EI) variation of Si-DLC nanocomposite with respect to flow rate of $\mathrm{C}_{2} \mathrm{H}_{2}$

The tribological behaviours of the Si-DLC nanocomposite with respect to various $\mathrm{C}_{2} \mathrm{H}_{2}$ flow rate have been discussed by calculating the elasticity and plasticity index which are represented as $\eta_{i}$ and $\eta_{p}$ respectively. The $\eta_{i}$ and $\eta_{p}$ have been computed by using equation 5 and equation 6 which are presented below [26]

$$
\begin{aligned}
& \eta_{\mathrm{p}}=\frac{A 1}{A 1+A 2} \\
& \eta_{\mathrm{i}}=1-\eta_{\mathrm{p}}
\end{aligned}
$$


Where A1 denotes the area under the loading unloading curve, whereas, A1+A2 denotes the area under loading curve. Both A1 and A2 are pictorially shown in fig. 10. Fig. 9 denotes the Plasticity Index (PI) and Elasticity Index (EI) variation of Si-DLC nanocomposite with respect to $\mathrm{C}_{2} \mathrm{H}_{2}$ flow rate.

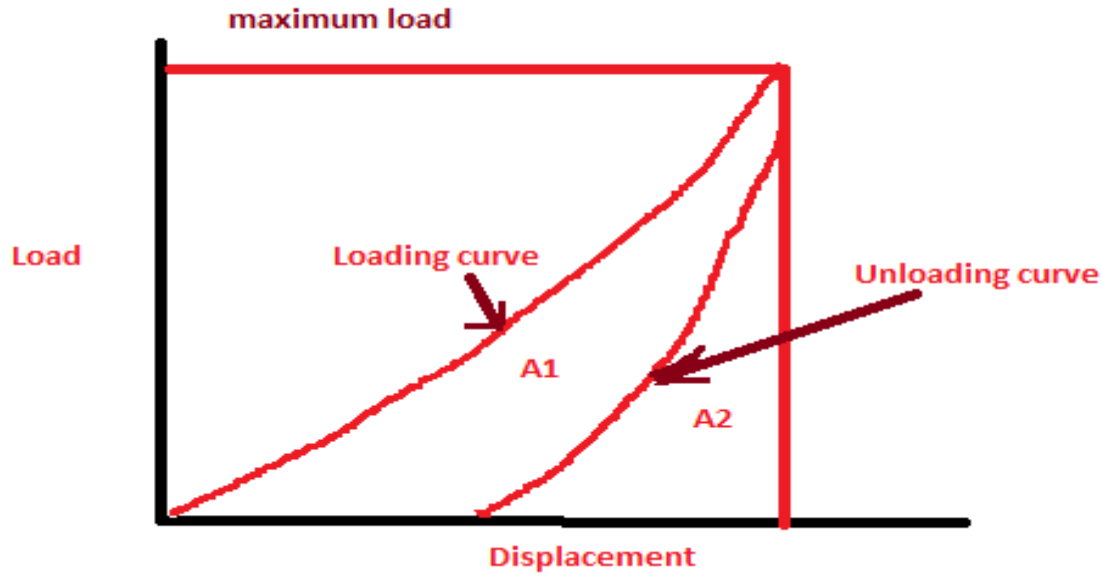

Fig. 10: Loading unloading curve to denotes A1 and A2.

Fig. 11 shows the COF of Si-DLC nanocomposite with respect to various flow rate of $\mathrm{C}_{2} \mathrm{H}_{2}$. From the fig. it is seen that the COF of the nanocomposite increases with increase of flowrates of $\mathrm{C}_{2} \mathrm{H}_{2}$. The minimum and maximum COF are observed as 0.065 and 0.082 for the $\mathrm{C}_{2} \mathrm{H}_{2}$ flow rate of 5 and $11 \mathrm{sccm}$, respectively. From the COF results it is observed that at low $\mathrm{C}_{2} \mathrm{H}_{2}$ flow rate the composite are smooth and at high flowrate the smoothness is decreasing. The small value of COF proves the smoothness of the composites, and the images obtained from AFM, depict that the average $\mathrm{Ra}$ of the nanocomposite increases with the increase the $\mathrm{C}_{2} \mathrm{H}_{2}$ flow rate. In previous works done by various researchers on DLC nanocomposite the minimum COF was achieved as 0.07 which shows that the present result is slightly better as compared to the previous work [27-29]. 


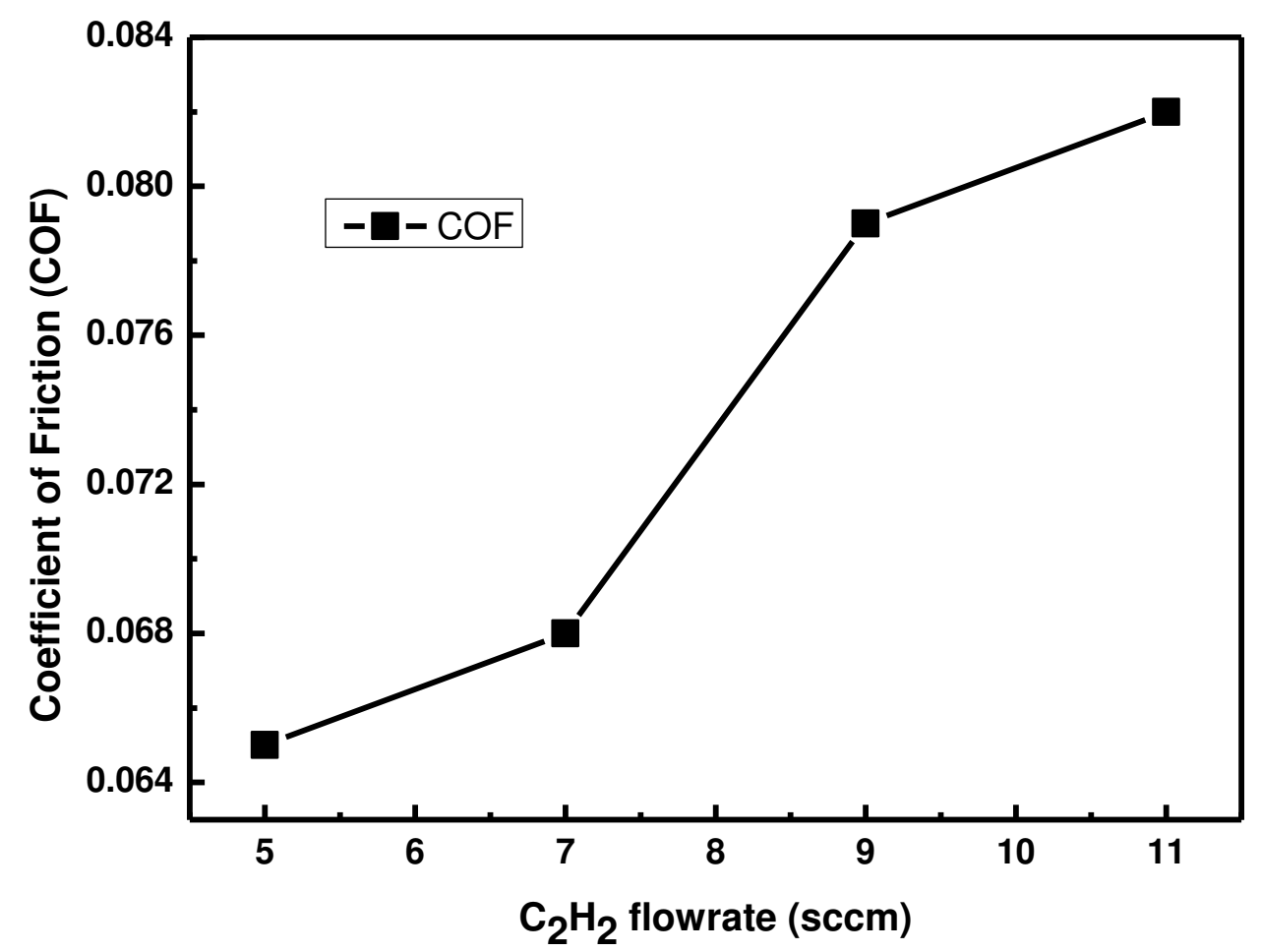

Fig. 11: COF of Si-DLC nanocomposite with respect to various $\mathrm{C}_{2} \mathrm{H}_{2}$ flow rate

\section{Conclusion}

In the current research work the detailed mechanical, tribological and morphological analysis of Si-DLC nanocomposite were done with respect to various $\mathrm{C}_{2} \mathrm{H}_{2}$ flow rates. The AFM and SEM confirm the smoothness of the nanocomposite at low $\mathrm{C} 2 \mathrm{H} 2$ flow rate and the smoothness get affected with increase the flow rate of $\mathrm{C}_{2} \mathrm{H}_{2}$. The EDS study revealed that the wt. \% of Si decreased with the increase of $\mathrm{C}_{2} \mathrm{H}_{2}$ flow rate. From the nanoindentation results it is observed that the $\mathrm{H}$ and $\mathrm{E}$ of the nanocomposite increases with the increase of $\mathrm{C}_{2} \mathrm{H}_{2}$ flowrate, and it may be due to the presence of more sp3 bond. From the values of $\mathrm{H} / \mathrm{E}, \mathrm{H}^{3} / \mathrm{E}^{2}, \mathrm{COF}$, plasticity index (PI) and elasticity index (EI) it is observed that Si-DLC nanocomposite has an excellent tribological properties. 
Ethics approval and consent to participate: The authors declare that we have no competing interests.

Consent for publication: On behalf of all the authors the corresponding author is giving consent for publications.

Availability of data and materials: All data and materials are original.

Competing interests: There is no conflict of interest.

Funding: This is a self-funding work.

Authors' contributions: V. Sakthi Murugan: Conceptualization, experimentation, Methodology, Software, and writing.

S. Madhu: writing and supervision

Acknowledgements: The authors would like to thank REST Society for Research International, Tamil Nadu, India for providing the experimental facilities.

\section{Reference}

1. H. Singh, G. Ramirez, O. Eryilmaz, A. Greco, G. Doll, A. Erdemir, Fatigue resistant carbon coatings for rolling/sliding contacts, Tribol. Int. 98 (2016) 172-178

2. Mutyala, K.C., Singh, H., Evans, R.D., and Doll, G.L., 2015. Deposition, characterization, and performance of tribological coatings on spherical rolling elements. Surface and Coatings Technology, 284, pp.302-309.

3. Kabir, M.S., Zhou, Z., Xie, Z. and Munroe, P., 2021. Designing multilayer diamond like carbon coatings for improved mechanical properties. Journal of Materials Science \& Technology, 65, pp.108-117.

4. Ghadai, R.K., Kalita, K., Mondal, S.C. and Swain, B.P., 2018. PECVD process parameter optimization: towards increased hardness of diamond-like carbon thin films. Materials and Manufacturing Processes, 33(16), pp.1905-1913

5. Ghadai, R.K., Kalita, K., Mondal, S.C. and Swain, B.P., 2019. Genetically optimized diamond-like carbon thin film coatings. Materials and Manufacturing Processes, 34(13), pp.1476-1487 
6. Kolawole, F.O., Varela, L.B., Kolawole, S.K., Ramirez, M.A. and Tschiptschin, A.P., 2021. Deposition and characterization of tungsten oxide (WO3) nanoparticles incorporated diamondlike carbon coatings using pulsed-DC PECVD. Materials Letters, 282, p.128645.

7. Ghadai, R.K., Singh, K., Sharma, A., Roy, M.K. and Swain, B.P., 2021. Mechanical and Tribological Properties of Metal Incorporated DLC Thin Film. In Nanostructured Materials and their Applications (pp. 229-263). Springer, Singapore.

8. Donnet, C. and Erdemir, A., 2007. Diamond-like carbon films: a historical overview. Donnet, C. und A. Erdemir (Herausgeber): Tribology of diamond-like carbon films, pp.1-10.

9. Jing, P.P., Ma, D.L., Gong, Y.L., Luo, X.Y., Zhang, Y., Weng, Y.J. and Leng, Y.X., 2021. Influence of Ag doping on the microstructure, mechanical properties, and adhesion stability of diamond-like carbon films. Surface and Coatings Technology, 405, p.126542.

10. Ghadai, R.K., Das, S., Kumar, D., Mondal, S.C. and Swain, B.P., 2018. Correlation between structural and mechanical properties of silicon doped DLC thin films. Diamond and Related Materials, 82, pp.25-32

11. S. Fujimoto, N. Ohtake, O. Takai, Mechanical properties of silicon-doped diamond like carbon films prepared by pulse-plasma chemical vapor deposition, Surf. Coat. Technol. 206 (2011) 1011-1015

12. Li, L., Song, W., Liu, J., Liu, Q., Wang, S. and Zhang, G., 2016. Nanomechanical and nanotribological behavior of ultra-thin silicon-doped diamond-like carbon films. Tribology International, 94, pp.616-623.

13. Liu, D.G., Zheng, L., Liu, J.Q., Luo, L.M. and Wu, Y.C., 2018. Structure and lubricated tribological behavior of silicon incorporated carbon nitride composite films deposited by magnetron sputtering. Diamond and Related Materials, 82, pp.115-123

14. Kim, J.I., Jang, Y.J., Kim, J. and Kim, J., 2021. Effects of silicon doping on low-friction and high-hardness diamond-like carbon coating via filtered cathodic vacuum arc deposition. Scientific reports, 11(1), pp.1-13.

15. Oliver, W.C. and Pharr, G.M., 1992. An improved technique for determining hardness and elastic modulus using load and displacement sensing indentation experiments. Journal of materials research, 7(6), pp.1564-1583. 
16. Das, S., Guha, S., Ghadai, R. and Sharma, A., 2021. Influence of nitrogen gas over microstructural, vibrational, and mechanical properties of CVD Titanium nitride (TiN) thin film coating. Ceramics International, 47(12), pp.16809-16819.

17. Ghadai, R.K., Das, S., Kalita, K., Shivakoti, I., Mondal, S.C. and Swain, B.P., 2021. Effect of nitrogen (N2) flow rate over the tribological, structural and mechanical properties diamondlike carbon (DLC) thin film. Materials Chemistry and Physics, 260, p.124082.

18. Zhao, J.F., Lemoine, P., Liu, Z.H., Quinn, J.P., Maguire, P. and McLaughlin, J.A., 2001. A study of microstructure and nanomechanical properties of silicon incorporated DLC films deposited on silicon substrates. Diamond and related materials, 10(3-7), pp.1070-1075.

19. Wang, J., Pu, J., Zhang, G. and Wang, L., 2013. Tailoring the structure and property of silicon-doped diamond-like carbon films by controlling the silicon content. Surface and Coatings Technology, 235, pp.326-332.

20. Chang, L. and Zhang, L.C., 2009. Deformation mechanisms at pop-out in monocrystalline silicon under nanoindentation. Acta Materialia, 57(7), pp.2148-2153.

21. Domnich, V., Gogotsi, Y. and Dub, S., 2000. Effect of phase transformations on the shape of the unloading curve in the nanoindentation of silicon. Applied Physics Letters, 76(16), pp.2214-2216.

22. Vodenitcharova, T. and Zhang, L.C., 2003. A mechanics prediction of the behaviour of mono-crystalline silicon under nano-indentation. International journal of solids and structures, 40(12), pp.2989-2998.

23. Ardigo, M.R., Ahmed, M. and Besnard, A., 2014. Stoney formula: investigation of curvature measurements by optical profilometer. In Advanced Materials Research (Vol. 996, pp. 361-366). Trans Tech Publications Ltd.

24. Janssen, G.C., Abdalla, M.M., Van Keulen, F., Pujada, B.R. and Van Venrooy, B., 2009. Celebrating the 100th anniversary of the Stoney equation for film stress: Developments from polycrystalline steel strips to single crystal silicon wafers. Thin Solid Films, 517(6), pp.18581867.

25. Wu, Y., Chen, J., Li, H., Ji, L., Ye, Y. and Zhou, H., 2013. Preparation and properties of $\mathrm{Ag} / \mathrm{DLC}$ nanocomposite films fabricated by unbalanced magnetron sputtering. Applied surface science, 284, pp.165-170. 
26. Patel, N.G., Sreeram, A., Venkatanarayanan, R.I., Krishnan, S. and Yuya, P.A., 2015. Elevated temperature nanoindentation characterization of poly (para-phenylene vinylene) conjugated polymer films. Polymer Testing, 41, pp.17-25.

27. Khun, N.W. and Liu, E., 2011. Investigation of structure, adhesion strength, wear performance and corrosion behavior of platinum/ruthenium/nitrogen doped diamond-like carbon thin films with respect to film thickness. Materials Chemistry and Physics, 126(1-2), pp.220-226.

28. Chen, T., Wu, X., Ge, Z., Ruan, J., Lv, B. and Zhang, J., 2017. Achieving low friction and wear under various humidity conditions by co-doping nitrogen and silicon into diamond-like carbon films. Thin Solid Films, 638, pp.375-382.

29. Erdemir, A. and Donnet, C., 2006. Tribology of diamond-like carbon films: recent progress and future prospects. Journal of Physics D: Applied Physics, 39(18), p. R311. 